\title{
Eddington e o encurvamento gravitacional da luz - com a tradução de Weighting Light do seu clássico livro Space, Time and Gravitation
}

Eddington and the gravitational bending of light — with the translation of "Weighting Light" from his classic book "Space, Time and Gravitation"

\author{
Marcel Novaes*1@, Nelson Studart $2,[0$ \\ ${ }^{1}$ Universidade Federal de Uberlândia, Instituto de Física, Uberlândia, MG, Brasil \\ ${ }^{2}$ Universidade Federal do ABC, Centro de Ciências Naturais e Humanas, Santo André, SP, Brasil \\ ${ }^{3}$ Universidade Federal de São Carlos, Departamento de Física, São Carlos, SP, Brasil
}

Recebido em 26 de Agosto de 2019. Aceito em 28 de Agosto de 2019.

\begin{abstract}
Arthur Eddington, um dos proponentes e principal articulador das expedições britânicas que realizaram observações do Eclipse de 1919 em Sobral e na Ilha de Príncipe, narrou suas impressões e os resultados obtidos nas placas fotográficas em capítulo de seu clássico livro Space, Time and Gravitation. Neste artigo, consta a tradução e comentários sobre a participação fundamental de Eddington na comprovação da deflexão gravitacional da luz, uma das predições da relatividade geral de Einstein.
\end{abstract}

Palavras-chave: Arthur Eddington, deflexão da luz, história da física, relatividade geral.

Arthur Eddington, one of the main proponents and principal manager of the british expeditions that observed the 1919 eclipse in Sobral and in the Island of Principe, put down his observations and the results obtained in the photographic plates in his classical book Space, Time and Gravitation. This article consists in translation and notes on the fundamental participation of Eddington in validating the gravitational deflection of light, one of the predictions from Einstein's theory of general relativity.

Keywords: Arthur Eddington, light deflection, history of phyics, general relativity.

\section{O "Buldogue" de Einstein}

Arthur Stanley Eddington (1882-1944), Professor Plumiano de Astronomia e Filosofia Experimental, uma das mais prestigiadas cátedras da Universidade de Cambridge, foi uma figura-chave nas expedições britânicas realizadas em 1919 para observar a deflexão da luz com o intuito de comprovar a teoria da relatividade geral, proposta por Einstein em 1915. Nessa época, Eddington era considerado um talentoso cientista com reputação na comunidade astronômica a partir de seu trabalho sobre a estrutura estelar, crucial para o desenvolvimento teórico da astrofísica. Tornou-se um dos principais porta-vozes da ciência no período entre as duas guerras mundiais e provocou controvérsias frequentes devido a seus ensaios sobre ciência e religião. [1,2]

A primeira menção de Eddington ao encurvamento da luz aparece com referência ao resultado do artigo de 1911 de Einstein. Com base no princípio de equivalência, Einstein deduziu que uma estrela vista próxima ao limbo do Sol estaria deslocada de 83 segundos de arco do Sol. Este valor ficou conhecido como o resultado newtoni-

*Endereço de correspondência: marcel.novaes@gmail.com ano para a deflexão da luz. [3] Na comunicação ao The Observatory, Eddington comenta: [4]

\begin{abstract}
"Seria muito difícil detectar essa deflexão até mesmo durante um eclipse total; mas tentativas estão sendo feitas. Um resultado decisivo, seja positivo ou negativo, seria de notável importância - nosso primeiro avanço concreto no entendimento da garvitação em mais de duzentos anos. Um resultado positivo significará que a gravitação foi derrubada de seu pedestal e deixou de pairar acima das outras forças da natureza."
\end{abstract}

Eddington se interessou pela teoria da relatividade geral por meio dos artigos de Einstein que lhe foram enviados pelo seu amigo, o astrônomo holandês Willem de Sitter. [5,6] Apesar do bloqueio britânico aos periódicos da Alemanha, alguns chegavam à Holanda, um país considerado neutro 1 Além disso, seu entusiasmo foi motivado pelos artigos de Sitter publicados no Monthly Notices of the Royal Astronomical Society (RAS) em

\footnotetext{
${ }^{1}$ Eddington disse a Chandrasekhar que essas cópias dos artigos de Einstein eram as únicas na Inglaterra e nos Estados Unidos até o final da Guerra. (1976).
} 
1916. Imediatamente Eddington se apaixonou pela teoria de Einstein e se tornou o incansável, e certamente o único, defensor da relatividade contra os ataques de cientistas proeminentes que a rejeitavam. Ele elucidou questões suscitadas nos artigos de de Sitter, dirimiu dúvidas acerca da nova matemática e defendeu a relatividade geral em debates na RAS. Tornou-se o "buldogue" de Einstein. Como apontado na comunicação de 1915 ao the Observatory, [4] Eddington acreditava que, com a relatividade geral, a gravitação estaria ligada diretamente com as demais forças da natureza.

\section{O Report}

Eddington publicou em 1919 o Report on The Relativity Theory of Gravitation [7], primeiro livro em língua inglesa sobre a teoria da relatividade geral, sob os auspícios da Royal Society of London. No prefácio da $1^{\mathrm{a}}$. Edição ${ }^{2}$ escrito em junho de 1918, ele adianta a possibilidade de testes da teoria:

"A teoria de Einstein teve sucesso em explicar a celebrada discordância no movimento do periélio de Mercúrio, sem introduzir nenhuma constante arbitrária; não há traço de concordância forçada em relação a essa previsão. Além disso, ela leva a conclusões interessantes em relação à deflexão da luz por um campo gravitacional e ao deslocamento das linhas espectrais do Sol, que podem ser testadas experimentalmente"

Após discutir a relatividade restrita, as relações do espaço, tempo e força, a álgebra tensorial (desconhecida da maioria dos físicos) e a lei de gravitação de Einstein, Eddington trata, no Capítulo 5 do Report, do que chamou de "fenômenos críticos": movimento do periélio de Mercúrio; deflexão de um raio de luz; deslocamento das linhas espectrais. O Report se estrutura com o objetivo de, tão diretamente quanto possível, expor a teoria desses fenômenos cruciais ${ }^{3}$ Ao final do capítulo, calcula a deflexão gravitacional da luz e obtém o resultado apontado por Einstein no artigo de 1916 da Relatividade Geral.

\section{Eddington e as expedições britânicas}

Einstein havia feito três previsões no artigo de 1916: o avanço do periélio de Mercúrio, cujo resultado havia impressionado os astrônomos, o desvio para o vermelho, de difícil comprovação experimental, e a deflexão gravitacional da luz. A observação desse desvio que podia ser feita

\footnotetext{
2 O prefácio da $2^{a}$. Edição é de dezembro de 1919.

3 É curioso encontrar um toque de ficção científica nessa observação de Eddington: "Pode ser de interesse notar que para um observador viajando com a [velocidade] da luz, $d x=d y=d z=0$, tal que $d t=d s=0$. Portanto, se um homem deseja atingir imortalidade e juventude eterna, tudo que tem a fazer é navegar pelo espaço com a velocidade da luz. Ele retornará à Terra, após lhe parecer ter decorrido um instante, e perceberá que muitos séculos se passaram."
}

em um eclipse solar era a última esperança de confirmar a teoria da relatividade geral.

Além da paixão de Eddington pela teoria de Einstein, e seu fervor pacifista, como Einstein, ele professava a fé dos quacres e atuava nas atividades contra a Grande Guerra patrocinadas pela Sociedade Religiosa dos Amigos. Lutou ainda contra mentalidade corrente de membros da Royal Society e RAS que não admitiam intercâmbio científico com a Alemanha. De acordo com o historiador Mathew Stanley: [1]
"A expedição ao eclipse, então, se tornou um evento carregado de significado político, moral e religioso. Einstein e a relatividade se tornaram ponto focal por meio do qual Eddington poderia avançar a ciência e o en- tendimento internacional."

Eddington conseguiu apoio contra essa mentalidade do Astronômo Real Frank Dyson, amigo e antigo colega do Observatório de Greenwich, que procurava permissão e recursos para organizar uma expedição para testar a teoria de Einstein durante o eclipse de 2019 4 Como deixou claro em carta ao matemático Hermann Weyl: [8]

\begin{abstract}
"Foi o entusiasmo de Dyson que deu impulso às expedições ao eclipse apesar de grandes dificuldades. Ele estava na época cético em relação à teora apesar de profundamente interessado; e ele percebeu sua grande importância."
\end{abstract}

Antes da partida, Eddington escreveu uma versão condensada do Report, realçando as bases teóricas e logísticas das observações. Deixou claro que, durante a totalidade do eclipse, o único foco da investigação seria testar a relatividade, mais especificamente demonstrar o peso da luz ou a não deflexão, mencionando o resultado nulo do experimento de Michelson-Morley: [9]

\begin{abstract}
"Não há necessidade de nos alongarmos a respeito das incertezas que afligem os observadores de eclipses; a possibilidade de clima desfavorável é a principal mas nem de longe a única causa de apreensão. Também não podemos ignorar a possibilidade de que alguma complicação desconhecida vá obscurecer a resposta à questão que está sendo investigada. Mas, se uma resposta clara for obtida, certamente será de grande interesse. Eu algumas vezes ponderei quais terão sido os sentimentos do Prof. Michelson quando seu experimento
\end{abstract}

\footnotetext{
4 Tentativa anterior para testar a teoria da gravitação de Einstein foi feita, após intensos esforços do próprio, na expedição à Criméia, liderada por Erwin Finlay-Freundlich durante o eclipse de 21 de agosto de 1914. Contudo, com a erupção da Guerra, teve os equipamentos apreendidos na Rússia. O astrônomo norte-americano Willam Wallace Campbell teve permissão para seguir com os planos, mas o tempo nublado impediu as observações.
} 
maravilhosamente projetado falhou em detectar os sinais esperados de nossa velocidade através do éter. Parecia que essa quantidade fugidia seria finalmente apreendida; mas o resultado foi nulo. Hoje podemos ver que um resultado positivo teria sido uma conclusão sem graça; foi o resultado negativo que originou um novo fluxo de conhecimento que revolucionou os conceitos fundamentais da física. Um resultado nulo não é necessariamente um fracasso. As presentes expedições ao eclipse podem pela primeira vez demonstrar o peso da luz; ou podem confirmar a estranha teoria de Einstein sobre o espaço não-Euclidiano ou podem levar a um resultado com ainda mais consequências - a ausência de deflexão."

Em 1933, Eddington contou para Chandrasekhar (1933) as expectativas da equipe acerca dos resultados, durante os preparativos para a expedição: [10]

"Da forma como o problema se nos apresentava, havia três possibilidades. Poderia não acontecer deflexão nenhuma; ou seja, a luz poderia não estar sujeita à gravitação. Poderia acontecer uma "meia deflexão", indicando que a luz estava sujeita à gravitação, como Newton havia sugerido, e obedecia à lei de Newton $\mathrm{Ou}$ poderia acontecer uma deflexão total, confirmando a lei de Einstein em lugar da de Newton. Eu me lembro de Dyson explicando tudo isso ao meu amigo Cottingham, que pegou a ideia geral de que, quanto maior o resultado, mais excitante seria ' $O$ que vai acontecer se obtivermos o dobro da reflexão? Então, disse Dyson, Eddington vai enlouquecer e você terá de ir para casa sozinho."

\section{O livro Space, Time and Gravitation}

Arthur Eddington abre o memorável livro Space time and Gravitation: An outline of the general relativity theory, [11] de 1920, com a hoje clássica foto dos instrumentos de Sobral, fornecido pelo astrônomo Charles Davidson que, juntamente com David Crommelin, compôs a expedição inglesa a Sobral.

O livro, "uma apresentação excelente, popular e abrangente da teoria geral da relatividade" como descrito por Hermann Weyl, e os demais Report [7] e The Mathematical Theory of Relativity [12] constituíram as únicas fontes do trabalho de Einstein na Grã-Bretanha e Estados Uni-

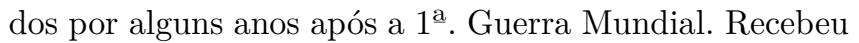
crítica favorável do influente matemático norte-americano Edwin B. Wilson: [13]

"Eddington tem um estilo agradável mesmo quando em exposições técnicas (...) Esse estilo é necessário quando se escreve uma versão semi-popular da nova teoria de Einstein. No geral, Eddington tem sucesso em tornar o assunto claro sem recorrer a muita matemática. É claro que alguém sem formação matemática além do ensino médio terá dificuldade em apreciar até mesmo o prólogo; mas um universitário que tenha estudado cálculo achará o livro acessível"

Nas próximas seções, apresentamos a descrição dos feitos das expedições britânicas e os resultados obtidos, feita no capítulo 7, "Weighting Light", do seu livro ${ }^{5}$

\section{Introdução ao "Pesando a Luz"}

\begin{abstract}
Questão 1. Os corpos não agem sobre a luz a distância, curvando seus raios, e não é essa ação (caeteris paribus) mais forte a pequenas distâncias?
\end{abstract}

\section{Newton Opticks.}

Chegamos agora ao teste experimental da influência da gravitação sobre a luz, discutida teoricamente no capítulo anterior. Não é o objetivo deste livro entrar em detalhes acerca do experimento; se seguíssemos esse plano de forma consistente, deveríamos resumir resultados das observações em poucas linhas. Mas foi esse teste em particular que chamou a atenção do público para a teoria da relatividade, e parece haver ampla curiosidade por informação. Vamos então contar a história das expedições dos eclipses com algum detalhe. Será uma quebra nos longos argumentos teóricos, e uma ilustração das importantes aplicações dessa teoria em observações práticas.

Temos que entender que havia duas perguntas a serem respondidas: primeiro, se a luz tem peso (como sugerido por Newton) ou se ela é indiferente à gravitação; segundo, caso ela tenha peso, se a magnitude da deflexão concorda com as leis de Einstein ou de Newton.

Já era sabido que a luz possui massa ou inércia como outras formas de energia eletromagnética. Isso se manifesta no fenômeno da pressão de radiação. Uma certa força é necessária para parar um raio de luz colocando um obstáculo em seu caminho; uma lanterna experimenta uma minúscula força de recuo assim como uma metralhadora ao disparar projéteis materiais. A força, prevista pela teoria eletromagnética ortodoxa, é extremamente pequena; mas experimentos delicados conseguiram detectá-la. Provavelmente essa inércia da radiação é de grande importância cósmica, tendo papel relevante no equilíbrio das estrelas mais difusas. É provável que seja responsável por distribuir o material do universo em estrelas de massas mais ou menos uniformes. As caudas dos cometas talvez sejam testemunhas do poder do momento da luz do Sol, que empurra as partículas menores ou mais absorventes.

\footnotetext{
5 Por questão de estilo, o texto é dividido em seções, que não estão presentes no texto original.
} 
É legítimo falar de um quilo de luz como falamos de um quilo de qualquer outra substância. Só que a massa de quantidades comuns de luz é extremamente pequena e calculei que, ao preço corrente, a companhia de energia elétrica teria de cobrar 300 milhões de libras esterlinas por quilo de luz. Toda a luz do Sol que chega até a Terra representa cerca de 160 toneladas diárias.

Talvez não seja fácil entender como um movimento ondulatório pode possuir inércia, e é ainda mais difícil entender o que significa dizer que tem peso. Talvez isso seja entendido melhor se colocarmos o problema de forma concreta. Imagine um corpo oco, cheio de radiação; a massa do corpo será a soma das massas do material e da energia radioativa em seu interior; uma força maior será necessária para deslocá-lo por causa das ondas de luz contidas nele. Agora vamos pesá-lo com uma balança. Seu peso será maior por causa da radiação contida, ou será apenas o peso do material sólido? No primeiro caso, temos que a luz claramente possui peso; e não é difícil deduzir o efeito desse peso para um raio de luz que se move livremente.

O efeito do peso é que a radiação no interior do corpo adquire a cada segundo um momento para baixo proporcional à sua massa. A longo prazo, esse momento é transferido ao material ao redor. Para um raio de luz livre no espaço, o momento extra se soma ao momento original e o momento total determina a direção do raio, que é defletido. A teoria de Newton não sugere nenhuma maneira de produzir essa deflexão, mas se contenta em prevê-la com base em princípios gerais. A teoria de Einstein sugere uma maneira, que é a variação na velocidade das ondas.

Até hoje a massa e o peso foram sempre associados em estrita proporcionalidade. Um teste muito importante já mostrou que essa proporcionalidade não está restrita à energia material. O material urânio contém muita radioatividade, presumivelmente de natureza eletromagnética, que libera lentamente. A massa dessa energia deve ser uma fração considerável da massa total do elemento. Mas foi mostrado por experimentos com uma balança de torção que a razão entre o peso e a massa do urânio é o mesmo que para todas as outras substâncias; de modo que a energia da radioatividade tem peso. Ainda assim, mesmo esse experimento lida apenas com energia eletromagnética aprisionada, e não temos justificativa para deduzir as propriedades da energia luminosa livre.

É fácil ver que um experimento terrestre não tem, atualmente, chance de sucesso. Se a massa e o peso da luz estão na mesma proporcional que na matéria, um raio de luz será defletido da mesma maneira que a trajetória de uma partícula material. Na Terra, uma bala de rifle, como todas as coisas, desce 5 metros no primeiro segundo, 20 metros em dois segundos, e assim por diante, abaixo de sua linha de vôo original; o rifle deve portanto ser apontado acima do alvo. A luz também iria baixar 5 metros no primeiro segundo $\sqrt{6}$ mas, como ela viaja 300 mil quilômetros durante esse tempo, a deflexão é imperceptível.

Na verdade, qualquer trajetória terrestre é percorrida tão rápido que a gravitação praticamente não tem tempo de exercer qualquer efeito.

O experimento deve ser, portanto, transferido para a vizinhança do Sol. Ali temos uma aceleração da gravidade 27 vezes mais intensa do que na Terra; e - o que é mais importante - o maior tamanho do Sol permite uma trajetória mais longa ao longo da qual a gravitação é razoavelmente forte. A deflexão nesse caso pode atingir a ordem de um segundo de arco, que, para um astrônomo, é uma quantidade relativamente grande.

Na Fig. 1, a linha EFPQ mostra a trajetória de um raio de luz de uma estrela distante $P$ que atinge a Terra $E$. A maior parte da deflexão do raio ocorre quando passa pelo Sol; e o curso inicial $P Q$ e o curso final $F E$ são praticamente retilíneos. Como o raio de luz entra no olho do observador ou no telescópio na direção $F E$, essa será a direção na qual a estrela aparece. Mas a direção verdadeira a partir da Terra é $Q P$, o curso inicial. Então, a estrela parece estar deslocada de sua posição verdadeira por um ângulo que é igual à deflexão total da luz.

Devemos notar que isso é verdade somente porque a estrela está tão longe que sua direção verdadeira em relação à Terra $E$ é indistinguível de sua direção a partir do ponto $Q$. Para uma fonte de luz no sistema solar, o deslocamento aparente da fonte não é igual à deflexão do raio de luz. É curioso que a atração da luz pelo Sol produza um deslocamento aparente da estrela para longe do Sol; mas está claro que é assim.

A deflexão afeta as estrelas visíveis na vizinhança do Sol e, por isso, a única chance de fazer essa observação é durante um eclipse total, quando a Lua bloqueia o clarão direto. Mesmo assim ainda há muita luz vindo da corona solar que fica por fora do eclipse. É necessário encontrar estrelas bem brilhantes próximas ao Sol, cujo brilho não se perca em meio à luminosidade da corona. Ademais, o deslocamento das estrelas só pode ser medido em relação a outras estrelas, de preferência mais distantes do Sol e menos deslocadas; precisamos então de um número considerável de estrelas brilhantes para servirem de pontos de referência.

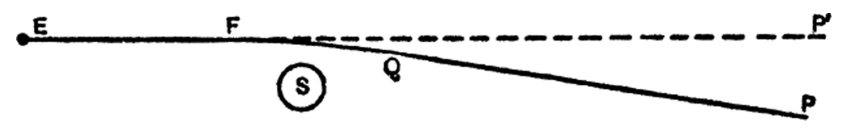

Figura 1: Deflexão da Luz ao passar perto do Sol (Fig. 16 no original).

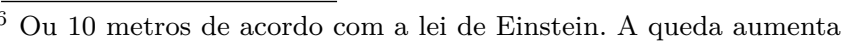
com a velocidade do movimento.
} 


\section{Um dia especial com cenário cósmico propício}

Em épocas supersticiosas, um filósofo natural que quisesse realizar um experimento importante consultaria um astrólogo para estabelecer o momento auspicioso. Mais razoável, o astrônomo de hoje consulta as estrelas e anuncia que o dia mais favorável do ano para pesar a luz é 29 de maio. A razão é que o Sol, em sua jornada anual em torno da eclítica, passa por vários conjuntos de estrelas de riqueza variável, mas em 29 de maio ele está no meio de uma região excepcional de estrelas brilhantes — parte das Híades - de longe a melhor região. Se esse problema tivesse aparecido em qualquer outro período da história, talvez fosse necessário esperar alguns milhares de anos para um eclipse total que ocorresse na data especial. Mas, por uma estranha sorte, um eclipse ocorreu no dia 29 de maio de 1919. Graças a uma curiosa sequência de eclipses, outra oportunidade semelhante vai aparecer em 1938; estamos em um ciclo muito favorável. Não estou sugerindo que seria impossível fazer o teste usando outros eclipses, mas o trabalho seria necessariamente mais difícil.

\section{Expedições e instrumentos}

O Astrônomo Real chamou a atenção de todos para essa oportunidade notável em março de 1917; preparações começaram a ser feitas pelo Comitê Conjunto da Sociedade Real e da Sociedade Astronômica Real para realizar as observações. Duas expedições foram enviadas para locais diferentes na linha de totalidade para minimizar o risco de falha por mau tempo. O Dr. A. C. D. Crommelin e o Sr. C. Davidson foram a Sobral, no norte do Brasil; O Sr. E. T. Cottingham e este autor foram à Ilha de Príncipe, no Golfo da Guiné, na África ocidental. Os equipamentos das duas expedições foram preparados no Observatório Greenwich, sob o cuidado do Astrônomo Real; o Sr. Davidson cuidou dos preparativos que foram o principal fator de sucesso de ambas as missões.

As circunstâncias das duas expedições eram um pouco diferentes e não seria possível falar das duas ao mesmo tempo. Vamos primeiro acompanhar a sorte dos observadores na Ilha de Príncipe. Eles tinham um telescópio de 11 pés e 4 polegadas (quase 3,5 metros) de distância focal. Em suas fotografias 1 segundo de arco (aproximadamente o maior deslocamento a ser observado) corresponde a cerca de 1,7 milímetros — de forma alguma uma quantidade desprezível. A abertura da objetiva era de 13 polegadas, mas foi usada com uma limitação para 8 polegadas para imagens mais claras. É necessário, mesmo quando a exposição é de apenas alguns segundos, levar em conta o movimento das estrelas pelo céu, movendo o telescópio junto com elas. Mas como é difícil montar da maneira necessária um telescópio longo e pesado em uma instalação temporária em uma parte remota do globo, a prática comum em eclipses é manter o telescópio rígido e refletir as estrelas nele através de um espelho celóstato - um espelho plano que gira na frequência precisa. Esse esquema foi adotado por ambas as expedições.

\section{As observações}

Os observadores tinham pouco mais de um mês na ilha para fazer seus preparativos. No dia do eclipse, o clima estava desfavorável. Quando a totalidade foi alcançada, o disco negro da Lua cercado pela corona era visível atrás das nuvens, assim como a lua às vezes aparece através das nuvens nas noites em que não podemos ver as estrelas. Não havia nada mais a fazer a não ser continuar com o projeto e torcer pelo melhor. Um observador ficou ocupado trocando as placas sucessivamente, enquanto outro cuidava da duração das exposições com uma tela em frente à lente objetiva para evitar mover o telescópio ${ }^{7}$

For in and out, above, about, below

'Tis nothing but a Magic Shadow-show

Played in a Box whose candle is the Sun

Round which we Phantom Figures come and go.

O palco toma toda a nossa atenção. Há um espetáculo maravilhoso lá em cima e, como as fotografias mais tarde revelaram, havia uma maravilhosa proeminência solar a cem mil milhas da superfície do Sol. Não havia tempo de olhar. Estávamos conscientes apenas da estranha meialuz da paisagem e do silêncio da natureza, quebrado pelos observadores e pelo metrônomo marcando 302 segundos de totalidade.

Dezesseis fotografias foram tiradas, com exposições variando de 2 a 20 segundos. As primeiras não mostravam estrelas, apesar de exibirem a notável proeminência; mas as nuvens diminuíram um pouco perto do fim da totalidade e algumas imagens apareceram nas placas finais. Em muitos casos, uma ou outra das estrelas principais estava faltando por causa das nuvens e a imagem era inútil; mas uma placa mostrava imagens boas de cinco estrelas, que eram adequadas para determinação. Uma medida foi feita no local alguns dias depois do eclipse em uma máquina de medida micrométrica. $\mathrm{O}$ problema era determinar como as posições aparentes das estrelas, afetadas pelo campo gravitacional do Sol, haviam mudado em relação a fotografias normais tiradas quando o Sol não estava no caminho. Fotografias para comparação haviam sido tiradas com o mesmo telescópio na Inglaterra, em janeiro. A fotografia durante o eclipse e a fotografia normal foram colocadas juntas na maquina de medida de modo que as imagens ficassem próximas 8 e as pequenas

\footnotetext{
7 Trecho do Rubaiyat de Omar Khayyam, título de seleção de poemas de Omar Khayyam, poeta, astrônomo e matemático persa do século XI, traduzido para o inglês por Edward Fitzgerald. Por dentro, por fora/por todo lado/É só um jogo por sombras encenado/Em um palco pela luz do Sol iluminado/No qual realizamos fantasmagórico translado.

8 Isso foi possível porque em Príncipe o campo de estrelas era refletido pelo espelho celóstato, enquanto na Inglaterra era fotografado diretamente.
} 
distâncias foram medidas em duas direções ortogonais. A partir daí os deslocamentos relativos das estrelas puderam ser determinados. Ao comparar as duas placas, várias correções precisaram ser feitas devidas a refração, aberração, orientação da placa, etc; mas, como isso também ocorre na determinação da paralaxe estelar, a qual demanda uma precisão muito maior, o procedimento era bem conhecido dos astrônomos.

\section{Comparação com os resultados}

Os resultados dessa placa mostraram um deslocamento, em acordo com a teoria de Einstein e em desacordo com a previsão newtoniana. Apesar do material ser parco comparado ao que esperávamos, o autor (que, devemos admitir, não era completamente isento) acredita que era convincente.

Foi somente depois do retorno à Inglaterra que outras confirmações apareceram. Quatro placas foram trazidas sem serem reveladas, porque eram de um tipo que não resistiria à revelação em clima quente. Uma delas mostrava estrelas suficientes e a medida mostrou a deflexão prevista por Einstein, confirmando a outra placa.

A possibilidade de erros sistemáticos assombra todas as investigações desse tipo. Como sabemos se não há algo no aparato que é responsável por essa deflexão aparente? A objetiva se moveu na viagem, introduzimos um espelho no sistema óptico, talvez o aumento de 50 graus de temperatura entre o clima do equador e o inverno inglês tenha causado algum dano. Para lidar com essas críticas, um grupo diferente de estrelas foi fotografado, à noite, em Príncipe e na Inglaterra na mesma altitude que o grupo do eclipse. Se a deflexão fosse instrumental, as estrelas nessas placas mostrariam os mesmos deslocamentos que aquelas nas placas no eclipse. Mas, ao medirmos essas placas, nenhum deslocamento foi encontrado. Isso parece ser evidência satisfatória de que o deslocamento observado durante o eclipse era realmente devido à presença do Sol e não a diferenças em condições instrumentais entre Inglaterra e Príncipe. De fato, a única possibilidade de erro seria uma diferença entre as condições noturnas em Príncipe quando as fotos foram tiradas e as condições na hora do eclipse. Isso não parece possível, porque a temperatura em Príncipe não varia mais do 1 grau entre o dia e a noite.

O problema parecia ter sido resolvido para além de qualquer dúvida; e era com confiança que aguardávamos o retorno da outra expedição, ao Brasil. O grupo do Brasil tinha encontrado melhor clima e tinha conseguido bem mais material em suas placas. Eles tinham permanecido por dois meses depois do eclipse para fotografar a mesma região antes da madrugada, sem o sol, a fim de poder comparar fotografias tiradas sob exatamente as mesmas circunstâncias. Um conjunto de fotografias foi tirado com um telescópio semelhante ao usado em Príncipe. Ademais, usaram um telescópio mais longo com abertura de 4 polegadas e distância focal de 19 pés (5,8 metros), como mostra a Fig. 2.

As fotografias obtidas com esse último foram decepcionantes. Apesar de mostrarem o número de estrelas esperadas (cerca de 12) e de várias placas terem sido obtidas, a definição das imagens foi estragada por alguma outra razão, provavelmente distorção do espelho celóstato por causa do calor. Os observadores estavam pessimistas em relação ao valor dessas fotografias; mas elas foram as primeiras a serem medidas ao voltarem à Inglaterra e os resultados foram surpreendentes em relação aos resultados de Príncipe. As medidas apontavam para uma concordância ótima com a meia deflexão, ou seja, o valor newtoniano que é metade do valor previsto pela teoria de Einstein. Parecia difícil que o parco material de Príncipe competisse com a quantidade de dados obtidos no céu limpo de Sobral. É verdade que as imagens de Sobral estavam condenadas, mas se era a ponto de invalidar a evidência que davam a esse respeito não estava claro; além disso, as imagens de Príncipe não tinham boa definição e estavam enfraquecidas pela presença das nuvens. Algumas de suas vantagens foram percebidas mais tarde. O forte delas era a validação contra erros sistemáticos fornecida pela comparação com fotografias de prova; não havia fotografias de prova em Sobral e, uma vez que era óbvio que a discordância entre os dois resultados dependia de erros sistemáticos e não da quantidade de dados, isso favorecia claramente os resultados de Príncipe. Ademais, em Príncipe não poderia haver efeitos adversos do calor dos raios do sol, porque o Sol havia se recolhido timidamente para atrás de um véu de nuvens. Outra vantagem eram as placas de prova de Príncipe, que davam uma determinação independente da diferença de escala do telescópio usado na Inglaterra e no eclipse; nas placas de Sobral essa diferença tinha sido eliminada pelo método da redução, com a consequência de que os resultados dependiam da medida de uma distância relativa muito menor.

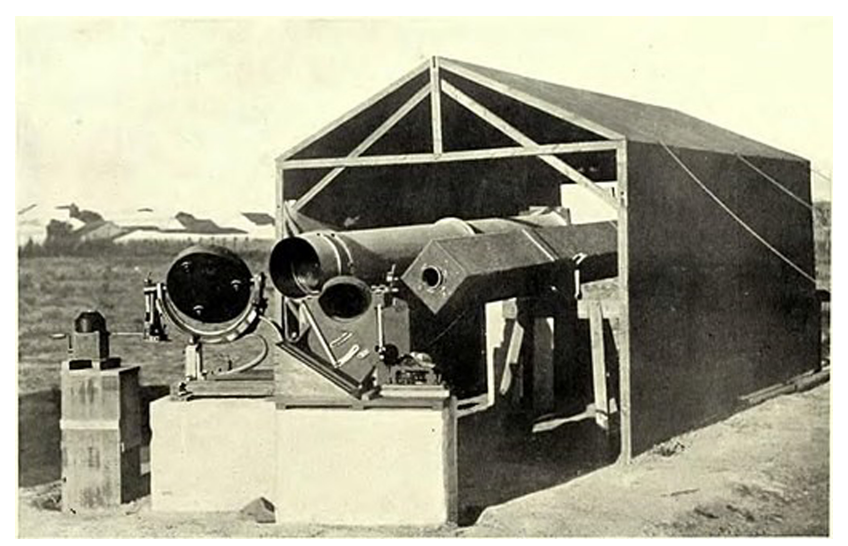

Figura 2: Os dois telescópios são mostrados e o fundo dos dois espelhos celóstatos que refletem o céu sobre eles. O mecanismo que dirige o espelho maior aparece no pedestal à esquerda. Fonte: Charles Davidson. (No original, o frontispício do livro). 
Restava um conjunto de sete placas tiradas em Sobral com a lente de 4 polegadas; as medidas haviam sido adiadas pela necessidade de modificar o micrômetro a fim de encaixá-las, pois eram de tamanho fora do padrão. Desde o começo ninguém teve dúvida de que a decisão final se basearia nelas, já que as imagens eram quase ideais e estavam em escala maior que as outras fotografias. O uso desse instrumento deve ter apresentado dificuldades consideráveis - o tamanho incomum do telescópio, a baixa velocidade das lentes que necessitavam exposições mais longas e um cuidado maior com as engrenagens, a maior escala que tornava o foco mais sensível a perturbações - mas os observadores obtiveram sucesso, e a perfeição dos negativos ultrapassou tudo o que poderíamos ter esperado.

\section{Confirmação da TRG}

Essas placas foram medidas e deram o veredito final confirmando definitivamente o valor de Einstein para a deflexão, em acordo com os resultados obtidos em Príncipe.

Devemos lembrar que a teoria de Einstein prevê uma deflexão de 1",74 no limbo do So $9^{9}$ decaindo com a distância desde o centro do Sol. A deflexão newtoniana é metade disso, 0",87. Os resultados finais (no limbo do Sol) obtidos em Sobral e em Príncipe com seus "possíveis erros acidentais" foram

$$
\text { Sobral 1",98 } \pm 0 ", 12 \text {, }
$$$$
\text { Principe 1",61 } \pm 0 ", 80 \text {. }
$$

É comum supor uma margem de segurança de cerca de duas vezes o erro provável de cada lado da média. A evidência das placas de Príncipe está, portanto, no limite para excluir a possibilidade de "meia deflexão", e as de Sobral a excluem com praticamente certeza. O valor obtido a partir do material encontrado em Príncipe não pode ser colocado mais do que um sexto acima daquele de Sobral, mas certamente torna mais difícil que a confirmação da teoria de Einstein seja criticada, já que foi obtida independentemente com dois instrumentos diferentes em lugares diferentes com tipos diferentes de checagens.

\section{Destaque para o telescópio de Sobral}

A melhor checagem dos resultados obtidos com a lente de 4 polegadas em Sobral é a notável concordância interna das medidas de diferentes estrelas. A deflexão teórica deve variar inversamente com a distância do centro do Sol; portanto, se graficarmos o deslocamento radial médio de cada estrela separadamente em função do inverso da distância, os pontos devem cair sobre uma linha reta. Isso

\footnotetext{
9 A deflexão prevista da luz desde o infinito até o infinito é pouco mais que $1 ", 45$, e do infinito até a Terra é um pouco menos.
}

é mostrado na Fig. 3, em que a linha tracejada mostra a previsão teórica de Einstein, os desvios estando dentro do erro experimental das determinações. Uma linha com metade da inclinação, representando a meia deflexão, seria claramente inadmissível.

Além disso, valores para a deflexão foram deduzidos de medidas em ascensão reta e em declinação, independentemente. Estavam em ótima concordância.

Um diagrama mostrando as posições relativas das estrelas é mostrado na Fig. 4. O quadrado mostra os limites

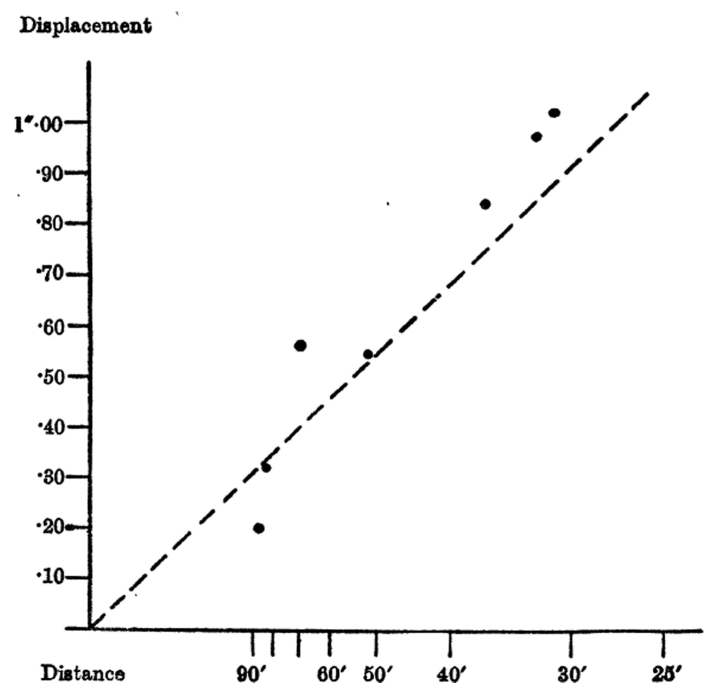

Figura 3: Deslocamento radial médio de cada estrela separadamente em função do inverso da distância. A linha tracejada mostra a previsão teórica de Einstein, e como os pontos devem cair numa linha reta, a concordância é ótima, estando os desvios dentro do erro experimental. (Fig. 17 no original).

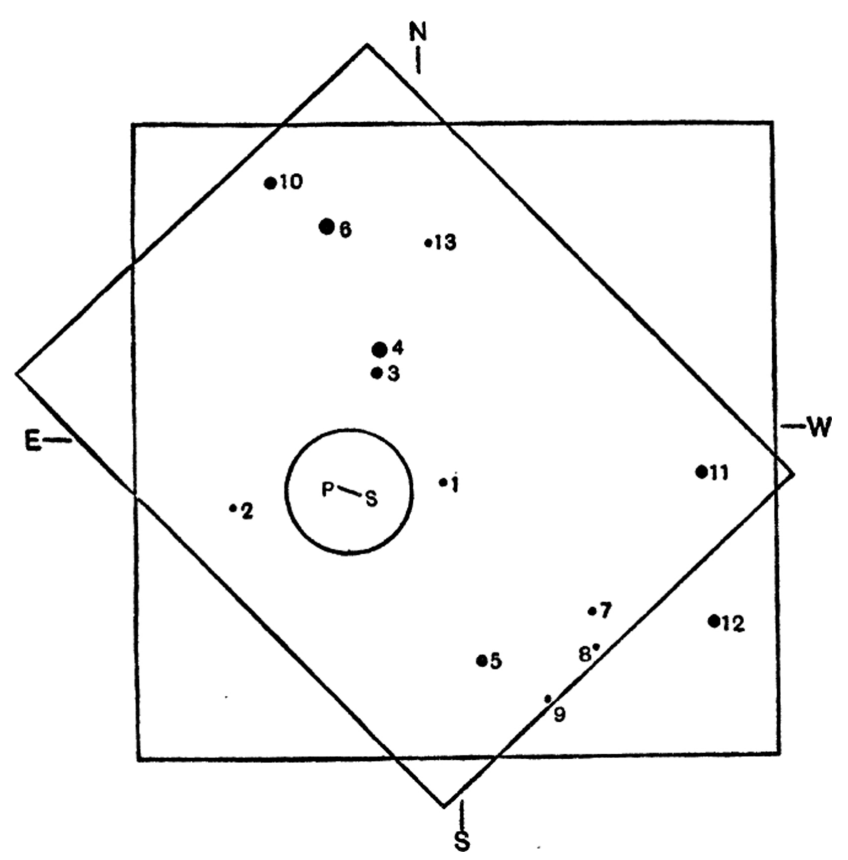

Figura 4: Diagrama mostrando as posições relativas das estrelas (Fig. 18 no original). 
das placas usadas em Príncipe, e o retângulo oblíquo mostra os limites da lente de 4 polegadas em Sobral. O centro do Sol se moveu de $\mathrm{S}$ para $\mathrm{P}$ nas $21 / 4$ horas entre as totalidades nas duas estações. O Sol está representado aqui para um momento mais ou menos intermediário.

As estrelas medidas nas placas de Príncipe são as de números 3, 4, 5, 6, 10, 11; as de Sobral são as 11, 10, 6, 5, 4, 2, 3 (na ordem dos pontos da esquerda para a direita na Fig. 3). Nenhuma delas era mais fraca que $6^{\mathrm{m}}, 0$, a mais brilhante sendo $\kappa^{1}$ Tauri (No. 4) com $4^{\mathrm{m}}, 5$.

\section{Críticas}

Objetou-se que, apesar de as observações estabelecerem uma deflexão da luz ao passar pelo Sol que é a prevista por Einstein, não é imediatamente óbvio que essa deflexão deva necessariamente ser atribuída ao campo gravitacional do Sol. Foi sugerido que pode não ser um efeito essencial do Sol enquanto corpo massivo, mas um efeito acidental devido à circunstância de que o Sol está envolto por uma corona que age como uma atmosfera refrativa. Seria uma estranha coincidência se essa atmosfera imitasse a lei teórica da maneira quantitativa exata mostrada na Fig. 3; e a essa sugestão nos parece despropositada.

Entretanto, a objeção pode ser enfrentada de modo mais direto. Já mostramos que o efeito gravitacional sobre a luz é equivalente ao produzido por um meio refrativo em torno do Sol e calculamos o índice de refração necessário. A uma altura de 400 mil milhas da superfície, o índice de refração teria de ser 1,0000021.Isso corresponde a ar a uma pressão de 1/140 atmosferas, hidrogênio a 1/70 atmosferas, hélio a 1/20 atmosferas. Parece óbvio que não pode haver matéria com essa densidade a tal distância do Sol. A pressão produzida na superfície do Sol por essas colunas de matéria seria da ordem de 10 mil atmosferas; temos evidências espectroscópicas de que não há pressão dessa ordem. Se for sugerido que essa massa talvez possa ser mantida por forças elétricas, o argumento da absorção fica ainda mais forte. A luz das estrelas fotografas durante o eclipse passou através de pelo menos um milhão de milhas de material com densidade dessa ordem — ou digamos o equivalente a 10 mil milhas de ar a pressão atmosférica. Sabemos os efeitos que tem a absorção de 5 milhas de atmosfera terrestre homogênea. Mas no eclipse as estrelas aparecem nas fotografias com seu brilho usual. Se o crítico insistir que o material em torno do Sol pode ser composto de algum novo elemento, com propriedades diferentes de qualquer outro material conhecido, podemos responder que o mecanismo de refração e absorção é o mesmo e que há um limite para a possibilidade de refração sem absorção apreciável. Finalmente, seria necessário que a densidade desse material diminuísse inversamente com a distância ao centro do Sol para fornecer a variação necessária no índice de refração.

Vários cometas conhecidos se aproximam do Sol dentro dos limites de distância considerados aqui. Se tivessem que passar através de uma atmosfera com a densidade necessária para causar o deslocamento, sofreriam enorme resistência. O Dr Crommelin mostrou que um estudo desses cometas estabelece um limite superior para a densidade da corona, o que torna o efeito refrativo desprezível.

\section{Conclusão}

Aqueles que consideram a lei de Einstein para a gravitação como uma dedução natural de uma teoria baseada em um número mínimo de hipóteses ficarão satisfeitos em descobrir que sua previsão notável é quantitativamente confirmada pela observação e que nenhuma outra causa apareceu para invalidar esse teste.

\section{Referências}

[1] M. Stanley, Isis 94, 57 (2003).

[2] M. Stanley, Einstein's war: How Relativity Triumphed Amid the Vicious Nationalism of World War I. (Dutton, New York, 2019).

[3] C. Lenzi, P. Pompéia e N. Studart, Rev. Bras. Ens. Fis. 41 (2019), unpublished.

[4] A.S. Eddington, The Observatory 484, 93 (1915).

[5] W. de Sitter, Monthly Notices of the Royal Astronomical Society 76, 699 (1916).

[6] W. de Sitter, Monthly Notices of the Royal Astronomical Society 77, 155 (1916).

[7] A.S. Eddington, Report on The Relativity Theory of Gravitation (Fleetway Press, London, 1920).

[8] D. Kennefick, Phys. Today 62, 37 (2009).

[9] A.S. Eddington, The Observatory 537, 119 (1919).

[10] S. Chandrasekhar, Notes Rec. R. Soc. London 30, 249 (1976).

[11] A.S. Eddington, Space time and Gravitation: An outline of the general relativity theory (Cambridge U.P., Cambridge, 1953).

[12] A.S. Eddington, The Mathematical Theory of Relativity (Cambridge U.P, Cambridge, 1923).

[13] E. Wilson, Bull. Amer. Math. Soc. 27, 182 (1921). 